\title{
Legal Protection of the Rights and Interests of Ethnic Floating Population in Cities
}

\author{
Jingjing $\mathrm{TaO}^{1, \text { a }}$ \\ ${ }^{1}$ Oxbridge College, Kunming University of Science and Technology, Kunming City, Yunnan Province, \\ China \\ aTao820608@126.com
}

Keywords: Ethnic Relations; Floating Population; Urban Minorities.

\begin{abstract}
With the development of the society, a large number of minority people have been pouring into the cities. They contribute to the urban construction and are facing the problems of employment, social security and children's limited education, etc. This article puts forward some legal suggestions to solve the problems of the urban ethnics. Therefore, we can provide our country with a strong foundation of national unity.
\end{abstract}

\section{Introduction}

In November, 2015, National Health and Family Planning Commission of PRC has issued China Population Development Report (2015) and pointed out that during the period of the 12th Five-Year plan, the average annual growth rate of China's floating population has increased about eight million. And the number has reached to 253 million at the end of 2014 with an increase of more than 14 million compared to that in 2013. The floating population in China tends to be stable. According to the statistics in 2014, 55\% of the floating population live in their residence more than 3 years. More than half of the floating population will tend to live in their residence in the future. Among them, some are the minority people. For instance, the number of the ethnics in Zhejiang Province has increased from 395,000 to 1,215,000. The number of the ethnics in Guangdong province has increased from 1,269,000 to 2,067,000. The number of the ethnics in Beijing has increased from 585,000 to 801,000 . [1] With the increase of the ethnics in cities, more and more social problems occur. For instance, employment, household register, children's education, customs and religious beliefs and so on. If these problems cannot be properly resolved, it will affect the national unity and the stability of the city. Therefore, it is necessary to provide the ethnics with necessary legal protection for their rights and interests, so that we can demonstrate the value system of the socialist harmonious ethnic relations.

\section{Present Situation of Rights and Interests Protection of the Ethnic Floating Population in Cities}

Employment inequality still exists; ethic migrant workers are difficult to get social security. The Constitution confers every citizen the right of equal employment. But now, the phenomena of regional protection and gender discrimination still exist. The discrimination against ethnic floating population in cities is even more common. For ethnic floating workers who come from remote areas, the occupational discrimination comes first in working environment. Employers separate different kinds of occupations, while some migrant workers with minority nationalities can only engage in dirty, hard and low laid activities. Job opportunities are firstly offered to local employees or workers come from cities, then to workers come from rural areas; ethic migrant workers have the least work opportunities. This is actually a system of employment discrimination which is unfair to ethnic floating population. They are deprived of employment opportunities. No intermediary agencies are willing to recommend them. Agencies worry about the damage of their own interests in case of contradictions. Thus, it is difficult for ethnic minority workers to find suitable jobs in cities. The unfair employment environment makes these workers difficult to get social security. These workers do not have permanent urban residence certificates, and in order to find jobs quickly, they have to 
accept the harsh conditions offered by employers. So in the future, their labor rights may be violated. At the same time, policies on minority floating population are difficult to be implemented; employees have urgent needs to get jobs, and are lack of legal awareness. Some employers use their shortcomings, and sacrifice their rights to make their own profits. Most migrant workers, even the independent traders, are lack of social insurance awareness; they would not buy social security by themselves. These comprehensive factors keep minority floating population from social security system.

Education rights of their children are restricted. Significant change happens in the flowing patterns. Nowadays the flowing of single individuals has become family migration. The results of a sampling survey conducted by National Bureau of Statistics of China can be seen as the table below. In 2014, the number of migrant workers who came to cities with their families was 35, 78 million. This phenomenon will inevitably lead to the problem of their children's education.

Units: Ten thousand people

\begin{tabular}{l|r|r|r|r|r}
\hline & \multicolumn{1}{|c|}{2010} & \multicolumn{1}{c|}{2011} & 2012 & \multicolumn{1}{c}{2013} & 2014 \\
\hline total peasant workers & 24223 & 25278 & 26261 & 26894 & 27395 \\
1. workers migrate & 15335 & 15863 & 16336 & 16610 & 16821 \\
(1) workers migrate by their own & 12264 & 12584 & 12961 & 13085 & 13243 \\
(2) workers migrate with their families & 3071 & 3279 & 3375 & 3525 & 3578 \\
2. locate peasant workers & 8888 & 9415 & 9925 & 10284 & 10574 \\
\hline
\end{tabular}

From the Investigation and Research Report of Floating Children in China, now there are about 20 million migrant children in China; $6.85 \%$ of them never go to school, $2.45 \%$ dropout from schools. 15.4\% migrant children from 8 to 14 years old are uneducated. The education of minority children from low income migrant families has become the difficulty and focus of solving the education problem of migrant children. Most of these children's parents are in low cultural levels, and do not have permanent urban residence certificates. Taking Kunming as an example. According to relevant policies, children in Kunming can attend to public primary schools which located in same area with their permanent urban residence certificates. Thus, minority children from migrant families cannot go to these public schools; they can only choose private schools nearby. However, the tuition fees of some private schools are higher than their family incomes. In result, the education rights of these children cannot be guaranteed.

\section{Problems in the Management of Ethnic Floating Population in China}

The biggest problem of managing the minority floating population in cities is the lack of legislation. In China, there are some policies and laws which can protect the rights and interests of floating population, such as the Labor Law, Payment of Wages Tentative Provisions for Peasant Workers from Construction Field, and regulations which can protect ethnic minorities, such as Regional National Autonomy Law, Work Regulations of Urban Ethnic Minorities. However, up to now, the state does not issue any laws or regulations which can protect minority floating population; there's no special legal norm which is applicable to the protection of rights and interests of minority floating population. Although both the Regional National Autonomy Law and the Work Regulations of Urban Ethnic Minorities belong to national legal system and are closely related to ethnic minorities, they are two parallel systems which have their own management scopes and objects. They are suitable to minority families registered in autonomous local areas or minority families with urban household registration. No one deals with minority floating population. So in the legal system of protecting rights and interests of minority people, the ethnic floating population is separated from ethnic minorities in national autonomous regions. This is another problem in the legal system which protects ethic floating population. In addition, although these two laws admit ethnic floating 
population, the related provisions and regulations are difficult to be implemented. For example, the sixteenth item of Regulations of Urban Ethnic Minorities regulates that, "relevant departments should provide convenient conditions for ethic migrant workers who come to cities to set up enterprises or engage in other legal business activities. The urban governments need to strengthen the education and management of these people, and protect their legal rights and interests. The ethic migrant workers should abide by local laws and regulations, and subject to the administration of urban government and relevant departments." But there are no corresponding sanction regulations, so the implementation people cannot be constrained. Also, the regulations are issued by the State Council, rather than National People's Congress or the Standing Committee of the NPC. Their legal effects are relatively low. Thus, the existing Regional National Autonomy Law and the Work Regulations of Urban Ethnic Minorities are not suitable to current situation and cannot solve the social problems of minority floating population in cities.

\section{Suggestions on Promoting the Legal Management of Ethic Floating Population in Cities}

Strengthening cooperation between different regions. At present, many cities have special systems to cope with disputes and relief for the ethnic minority. But most of these workers tend to resort their hometown governments. For example, there's a survey of 125 Uygur workers in Tianjin. According to the survey, when their rights are infringed, workers have following ways to solve the problem. (1) 10 people ask for helps from native companions, accounting for 8\%; (2) 122 people ask for helps from their hometown governments, accounting for 97.6\%; (3) 10 people ask for helps from news media, accounting for $8 \%$; (4) 4 people ask for helps from the city government, accounting for 3.2\%; (5) 13 people seek legal counsel, accounting for 10.4\%. [2] Therefore, we should actively promote cooperation between different departments and regions.

Intensifying the formulation of Ethic Floating Population Protection Law. There are no laws or regulations which can protect the rights and interest of minority population in cities. The existing policies and laws, though deal with ethic relations, are lack of specific regulations. Some provisions and regulations are difficult to be implemented, since the sanction and supervision items are missing. Their legislative levels are low, and no practical consequence can be found. [3] So it is necessary to strengthen the formulation of Ethic Floating Population Protection Law. The existing Work Regulations of Urban Ethnic Minorities are issued by the State Council. It protects the rights and interests of minority families registered in autonomous local areas or minority families with urban household registration. Regulations which deal with minority floating population are missing. Thus, the Ethic Floating Population Protection Law, which practically deals with the protection of rights and interest of minority floating population, should be issued. It can be combined with Regional National Autonomy Law to complete the legal system. The system can promote the economic and social development of regional national autonomous regions, and protect the rights and interest of minority floating population in cities and multi-ethnic places. Ethic Floating Population Protection Law can provide legal protection to floating population, especially floating population in cities. It is also the basis of legislation and execution of laws which guarantee the rights of ethnic migrant workers. In accordance with the spirit of this law, the State Council can develop relevant plans and specific operational methods for cities and national communities. Then ethnic cultures can be developed, specific measures on education projects can be made. The practical problems related to the interests of floating population in cities can be solved. Then, violent events against these ethnic minorities in cities can be reduced, their basic rights of survival and development can be ensured. In this way, the government can promote the spirit of human rights and law ruling society. People from different nationalities create Chinese culture together, and now we should unite them to realize the national rejuvenation.

Strengthen the supervision and law enforcement to effectively protect the legal rights and interests of minority floating population in cities. To ensure the legal rights and interests of the minority nationality, both legislative works and law enforcement are important. Ethnic Affairs Commission should cooperation with public security and urban management departments. Generally speaking, for migrant workers with stable works, their rights and interests are better protected. The 
most difficult part is urban minorities with no fixed residence or fixed jobs. The cooperation between public security, industry and commerce, urban management, transportation and other departments should be strengthened to establish information exchange system. Regular and irregular inspections on law enforcement statuses are necessary. These measures can resolve conflicts and protect legal rights of minority floating population. The supervision mechanism should be lead by People's Congress of all levels as well as their standing committees. They have the obligation to ensure the correct enforcement and implementation of the Constitution and related laws, administrative rules and regulations. The People's Congress of all levels should give full play to their supervisory powers, and determine special standards to further clarify the inspection and supervision on the implementation and enforcement of law related to the rights and interests of minority floating population. Based on the observation of ethnic floating population, special investigations which deal with issues of business, equal employment, social security and children's education can be carried out to increase the working efforts of governments and other sectors. Secondly, the supervision mechanism should also be lead by judiciary authorities at all levels. Prosecutors should supervise the implementation of ethic laws. Their works mainly include the responsibility investigation for any state organs or citizens who violate ethic laws. People who commit crimes should be prosecuted. People who do not commit crimes should be transferred to related party organs and being punished. The people's court also plays a role in the supervision of implementation when hearing cases related to ethic laws. In short, with the development of the democratic politics in our country, the function of various departments at all levels become more and more important. Supervision on the implementation of related laws can also be realized through people and news media. These methods have unique merits which cannot be replaced by other organs.

\section{References}

[1] D.H. Wu, X.H. Huang, Legal protection of the rights and interests of ethic floating population in cities from the perspective of ruling by law in China, J. Journal of Guizhou Normal University. 2 (2015).

[2] C.B. Liu, C. Zhang, Investigation report on employment and living conditions of the Uighur population in Tianjin, J. Ethnic Studies. 3 (2009).

[3] Y.X. Ma, Research on the legal protection of rights and interests of ethnic groups in cities, in: Ethnic Law Study, vol.7, pp.126-136.

[4] D.H. Wu, P. Wang, Report on the development of Chinese national legal rule, Minzu University of China press, Beijing, 2012.

[5] Z.F. Zhu, An analysis of compulsory education policy for migrant workers' children from the perspective of social welfare policy, J. Research in Education Development. 4 (2011). 